\title{
Repeated Stimulation of CRF Receptors in the BNST of Rats Selectively Induces Social but not Panic-Like Anxiety
}

\author{
Younglim Lee*,', Stephanie Fitz', Philip L Johnson' and Anantha Shekhar' \\ 'Department of Psychiatry, Institute of Psychiatric Research, Indiana University, Indianapolis, IN, USA
}

\begin{abstract}
Increased extra-hypothalamic corticotrophin-releasing factor (CRF) neurotransmission has been suggested as one putative factor in the pathophysiology of anxiety disorders. We have previously reported that administering repeated subanxiogenic doses (termed 'priming') of the CRF receptor agonist urocortin I ( $U \mathrm{cnl}$ ) into the basolateral amygdala (BLA) of rats elicited long-lasting behavioral changes in social interaction (SI) and elevated plus maze (EPM) tests of anxiety. Although substantial similarity exists, the bed nucleus of the stria terminals (BNST) and the amygdala are thought to play distinct roles in anxiety responses. Rats primed with UcnI in the BLA not only demonstrated increased anxiety-like behaviors, but also physiological sensitivity to intravenous sodium lactate infusions, which is seen in subjects with panic or posttraumatic stress disorders, but not social or generalized anxiety disorders. In the present study, we tested if similar priming with subanxiogenic doses of $U_{\mathrm{cn} I}$ in the BNST of rats will induce either chronic anxiety or sensitivity to sodium lactate. After determining the dose of $U \mathrm{cnl}$ that is subanxiogenic when injected into the BNST, repeated intra-BNST injections of this subanxiogenic dose of $\mathrm{Ucnl}$ ( $6 \mathrm{fmol} / / 00 \mathrm{nl}$ ) elicited persistent (present even after 4 weeks) anxiety-like responses in the SI but not EPM test. Prior local injection of a CRF receptor antagonist, astressin, into the BNST blocked this effect. Unlike UcnI priming in the BLA, rats primed in the BNST showed no cardiovascular changes following lactate infusion. Thus, BNST priming appears to selectively model the pathophysiology of subjects with anxiety syndromes like social anxiety, which are not lactate sensitive.

Neuropsychopharmacology (2008) 33, 2586-2594; doi: I0. I038/sj.npp. I 301 674; published online 20 February 2008
\end{abstract}

Keywords: CRF; stress; BNST; anxiety; sensitization; lactate

\section{INTRODUCTION}

The bed nucleus of the stria terminalis (BNST) is thought to be a key structure for mediating anxiety-like responses elicited by unconditioned or ethologically valid threats (Lee and Davis, 1997; Walker and Davis, 1997; Davis and Shi, 1999; Fendt et al, 2003), and is a key structure that relays and integrates limbic and autonomic information related to stress responses (Cullinan et al, 1993; Forray and Gysling, 2004; Herman et al, 2004). The BNST has also been identified as an area critical for stress-induced reinstatement of drug-seeking behaviors, and for the increased anxiety associated with protracted withdrawal (Erb and Stewart, 1999; Leri et al, 2002; Aston-Jones and Harris, 2004).

Corticotrophin-releasing factor (CRF) may play a critical role in mediating some types of anxiety responses. Thus, CRF given centrally induces anxiogenic behaviors in various animal models, such as open field (Britton et al, 1982; Liang

\footnotetext{
*Correspondence: Dr Y Lee, Department of Psychiatry, Institute of Psychiatric Research, Indiana University School of Medicine, 79I Union Drive, Indianapolis, IN 46202, USA, Tel: + I 317278 9047, Fax: + I 317278 9739, E-mail: yl7@iupui.edu

Received 20 August 2007; revised 5 December 2007; accepted 6 December 2007
}

and Lee, 1988; Takahashi et al, 1989), EPM (Baldwin et al, 1991), conflict test (Britton et al, 1985), social interaction (SI) (Dunn and File, 1987), acoustic startle (Swerdlow et al, 1986; Liang et al, 1992), and conditioned fear response (Cole and Koob, 1988). So far, two CRF receptor subtypes, $\mathrm{CRF}_{1}$ and $\mathrm{CRF}_{2}$, have been identified (De Souza et al, 1985; Chalmers et al, 1995; Perrin and Vale, 1999; Dautzenberg and Hauger, 2002). $\mathrm{CRF}_{1}$ is widely distributed throughout central nervous system, whereas $\mathrm{CRF}_{2}$ has more restricted distribution, primarily to subcortical regions (Chalmers et al, 1995; Van Pett et al, 2000). Within the extended amygdaloid complex, the BNST contains both $\mathrm{CRF}_{1}$ and $\mathrm{CRF}_{2}$ (Chalmers et al, 1995).

Previous studies from our laboratory showed that repeated daily injections (termed 'priming') into the basolateral nucleus of the amygdala (BLA) of the CRF receptor agonist urocortin 1 (Ucn1) at a dose that is lower than the one which elicits anxiety-like responses in the SI test (referred to as a 'subthreshold dose') induces a longlasting behavioral change. Thus, a single injection of $6 \mathrm{fmol}$ of Ucn1 failed to reduce SI acutely, whereas it suppressed SI significantly and persistently following five injections. More interestingly, only the Ucn 1 and not vehicle-primed rats exhibited increased behavioral and cardiovascular activation following intravenous sodium lactate infusions (Sajdyk et al, 1999; Rainnie et al, 2004), a response similar to certain 
subtypes of anxiety disorders such as panic and posttraumatic stress disorders (Cowley and Arana, 1990; Jensen et al, 1997). Given the putative involvement of the BNST in anxiety responses, we hypothesized that acute stimulation of CRF receptors within the BNST will increase anxiety in rats, and repeated stimulation of CRF receptors within the BNST will elicit a persistent and unique profile of anxietylike behaviors. To this end, we investigated (1) the effects of injecting different doses of Ucn 1 into the BNST and determine a subthreshold dose for eliciting anxiety-like responses; (2) the effects of repeated daily intra-BNST injections of such a subthreshold dose Ucn1 (Ucn1 priming); and (3) the changes in lactate sensitivity following Ucn1 priming of the BNST.

\section{MATERIALS AND METHODS}

\section{Animals}

Male Wistar rats (275-300 g; Harlan Laboratories, Indianapolis, IN) were used in these experiments. Upon arrival, the animals were housed individually in a temperature-controlled room $\left(22^{\circ} \mathrm{C}\right)$ and had access to food and water ad libitum. The room was maintained at $12-12 \mathrm{~h}$ light/dark cycle with light on at $0700 \mathrm{~h}$. Animal care procedures were conducted in accordance with the National Institutes of Health Guidelines for the Care and Use of Laboratory Animals and the Guidelines of the Indiana UniversityPurdue University Indianapolis Institutional Animal Care and Use Committee.

\section{Surgical Procedure}

BNST cannulation. Surgeries were conducted on the rats at least 1 week following arrival from the supplier. Rats were anesthetized using an isoflurane system (MGX Research Machine; Vetamic, Rossville, IN) prior to and during surgeries. Rats were mounted on a stereotaxic instrument (Kopf Instruments, Tujunga, CA) and chronic microinjection cannulae were unilaterally implanted into the BNST as follows. A small incision was made on the head and the skin was retracted. Using a stereotaxic arm, a stainless steel guide cannulae $(26 \mathrm{G})$ was lowered to the following coordinates (AP: 1.0 ; ML: $+/-2.5$; DV: -8.0 with manipulator arms at $10^{\circ}$, incisor bar at +5.5$)$. The guide cannulae were secured with three $2.4 \mathrm{~mm}$ stainless steel screws and dental cement. Once dry, the incision was sutured and the guide cannulae were sealed with dummy cannulae (Plastics One, Roanoke, VA). The rats were allowed to recover in their home cages for at least 5 days prior to any behavioral testing.

Implantation of telemetry probes. The mean arterial pressure (MAP, $\mathrm{mm} \mathrm{Hg}$ ) and heart rate ( $\mathrm{HR}$, beats/min) were measured by a femoral arterial line connected to a telemetric probe, which contained a pressure transducer (Cat no C50-PXT, Data Science International (DSI), St Paul, $\mathrm{MN}$ ), and were monitored by DSI dataquest software. The detailed procedure for telemetry probe implantation surgeries has been published elsewhere (Shekhar et al, 1996). Briefly, the animals were anesthetized with isoflurane and $1-1 \frac{1}{2}$ inches incision was made above the region where the femoral artery exits the abdomen. Following identification of the artery, a small incision was made on the artery and the end of a catheter connected to the telemetry probe was inserted and secured. The main body of the telemetry probe was routed into the abdominal cavity and secured into place by closing the opening by sutures.

\section{Experimental Drugs}

Astressin and urocortin 1 (Sigma-Aldrich, St Louis, MO) were dissolved utilizing a vehicle of $1 \%$ bovine albumin in distilled water.

\section{Behavioral Tests}

Social interaction test. The SI test is an accepted measure of anxiety (File, 1980) and a modified version has been used extensively in our laboratory (Sanders and Shekhar, 1995a, b; Shekhar and Katner, 1995; Sajdyk and Shekhar, 1997). The apparatus was a solid wood box $(91.44 \mathrm{~cm}$ long $\times 91.44 \mathrm{~cm}$ wide $\times 30.48 \mathrm{~cm}$ high) with an open roof. A video camera was fixed above the box and all behavioral tests were videotaped. An experimental rat and a novel partner rat were placed simultaneously in the SI box, and the amount of time the experimental rat spent in selfinitiated or fully participatory SI (ie, making face-on physical contact, such as grooming, sniffing, and playful contacts) with the partner rat was recorded for $5 \mathrm{~min}$. All testing was carried out under low light conditions (40-watt red light located above the SI box), during light phase of the day, between 0900 and $1300 \mathrm{~h}$.

Elevated plus maze test. The apparatus was made out of black Plexiglas (Hamilton Kinder, San Diego, CA). The maze had four arms $(11 \mathrm{~cm}$ wide and $50 \mathrm{~cm}$ long) with a center platform $(11 \times 11 \mathrm{~cm})$. One pair of opposing arms had walls $(40 \mathrm{~cm}$ high), thus creating a dark compartment that the rats naturally prefer. This entire maze was elevated to $100 \mathrm{~cm}$ above ground, using a pedestal made of square aluminum pipes. For the test session, the animals were introduced into the center platform facing one of the open arms, and time spent in exploring open arms over 5-min test session was recorded and scored using an automated photobeam scoring system. The total distance traveled by the rat was also recorded to measure locomotor responses.

\section{Experimental Protocol}

Experiment 1-An acute injection of Ucn1 into the BNST, but not to an adjacent area, will induce anxiety in rats. Following $72 \mathrm{~h}$ of postoperative recovery, the rats were habituated by placing them individually into the SI box for 5 min $(n=6)$. Twenty-four hours later, the rats were tested in the SI test as described above (baseline SI). Forty-eight hours later, the animals received a unilateral intra-BNST injection of either 0 (vehicle), 20 , or $100 \mathrm{fmol}$ of Ucn1. Thirty minutes after each intra-BNST injection, the animals were placed in the SI test. All intra-BNST injections were made using a $10 \mu \mathrm{l}$ Hamilton syringe placed on an infusion pump (model PHD 2000, Harvard Apparatus, Holliston, MA). The drugs were injected in a volume of $100 \mathrm{nl}$ (over $30 \mathrm{~s}$ ), and the injector remained in place for an additional 
minute to ensure full delivery. The rats received all three doses of Ucn1 in a counter-balanced order and were tested in the SI test following each injection. The interval between injections was $48-72 \mathrm{~h}$.

To control for the possibility that the effects of intraBNST injections of Ucnl were not due to spread of drug into structures adjacent to the injection area, in a separate set of rats, similar doses of Ucn1 (0 (vehicle), 20 or $100 \mathrm{fmol}$ ) were also injected into the nucleus accumbens $(n=4)$. Again, these rats were tested in the SI test at $30 \mathrm{~min}$ following each injection.

Experiment 2: Repeated injections of Ucn1 into the BNST will lead to long-lasting anxiety in rats. All rats received BNST cannulations, and were allowed to recover for 5 days ( $n=6 /$ treatment group). On day 6 , the rats were habituated to the SI box for $5 \mathrm{~min}$. On day 7, the rats received a baseline SI test without injection, and were divided into two groups with comparable levels of baseline SI time. On day 9, one group of rats was injected with a subthreshold dose of Ucn1 $(6 \mathrm{fmol} / 100 \mathrm{nl} / 30 \mathrm{~s} /$ day; determined by considering results of experiment 1 above and Sajdyk et al, 1999), while the second group was injected with vehicle for 5 consecutive days. On injection days 1 and 5, the rats were also placed in the SI test at $30 \mathrm{~min}$ postinjection. Forty-eight hours after the last injection, the rats were placed in the EPM test. The rats were subsequently evaluated in the SI test once a week for an additional 4 weeks.

Experiment 3: Pretreatment with a CRF antagonist will block development of Ucn1 priming in the BNST. In another set of rats ( $n=6 /$ treatment group) the priming procedure was identical with that described above, except that the rats were injected locally with vehicle or astressin (a nonselective CRF antagonist; $120 \mathrm{fmol} / 100 \mathrm{nl} / 30 \mathrm{~s}$ once a day) $30 \mathrm{~min}$ before receiving daily Ucn $1(6 \mathrm{fmol} / 100 \mathrm{nl} /$ 30 s/day) or vehicle injections into the BNST for 5 days. On injection day 1 and 5, the animals were again tested in SI at 30 min following Ucn1 injection.

Experiment 4: Ucn1 priming of the BNST will not increase sensitivity to a subsequent challenge with sodium lactate. Three groups of rats received telemetry probe, intravenously (i.v.) catheter and unilateral BNST cannula implantation ( $n=5 /$ treatment group). The detailed procedure for i.v. catheterization surgeries has been published elsewhere (Shekhar et al, 1996). The rats were allowed to recover and then habituated to a SI box for $5 \mathrm{~min}$. On the next day, HR and MAP were measured using the telemetry probe for 30 min (sampling every $10 \mathrm{~s}$ ). Immediately after this baseline reading, the animals were i.v. infused with either physiological saline (Bessie Medical, West Chester, $\mathrm{OH}$ ) or sodium lactate $(0.5 \mathrm{M}, 10 \mathrm{ml} / \mathrm{kg}$ : Bessie Medical) over $15 \mathrm{~min}$. HR and MAP were measured throughout the i.v. infusion. Upon cessation of i.v. infusion, the animals were placed in the SI test. Forty-eight hours after this initial testing, the rats were subjected to the second baseline test session with a cross-over i.v. infusion. For instance, rats that received saline infusions in the first baseline session were tested with sodium lactate in the second baseline test. The rats were matched and divided into three groups with similar levels of SI. Twenty-four hours after this matching, one group of animals received five daily intra-BNST injections of Ucn 1 ( $5 \mathrm{Ucn} 1$ group; $6 \mathrm{fmol} / 100 \mathrm{nl} /$ day/5 days) and the second group received daily five injections of vehicle. The third group of animals only received handling during initial 2 days of injection, and received daily three injections of Ucn1 into the BNST thereafter $(3 \mathrm{Ucn} 1$ group; $6 \mathrm{fmol} / 100 \mathrm{nl} /$ day $/ 3$ days). On the last day of injection, all animals were tested in SI $30 \mathrm{~min}$ after injection. Following this five daily intra-BNST injection regimen, the rats were allowed to rest for $78 \mathrm{~h}$, and post-BNST injection lactate sensitivity was tested using an identical procedure described above. Again, HR and MAP were measured before and during the i.v. infusion, and an SI test was given immediately after the i.v. infusion. All rats were tested with either i.v. infusion of saline or lactate in a counter-balanced design, and the test-retest interval was $48 \mathrm{~h}$.

Previously, we reported that daily three injections of Ucn 1 into the expand basolateral amygdala (BLA) suppressed SI only transiently, but increased sensitivity to sodium lactate significantly (Sajdyk et al, 1999). Thus, in contrast to the long-lasting anxiety observed following daily five Ucn1 injections, daily three Ucn1 injections suppressed SI time at 30 min postinjection, but this reduction did not persist at postinjection day 2 . Interestingly, these animals that received daily three injections of Ucn1 into the BLA showed significant elevation in HR and MAP following sodium lactate infusion, suggesting enhanced sensitivity to sodium lactate (Sajdyk et al, 1999). Therefore, the experimental design for the present study included a 3-day intra-BNST injection group to investigate possible increase in responses sensitivity to sodium lactate infusion without lasting shift in baseline anxiety.

\section{Statistical Analysis}

All behavioral data were represented as mean \pm SEM. For the acute Ucn1 injection studies, one-way repeated analysis of variance (ANOVA), using Ucn1 as the main factor, and injection number, doses and time as repeated measures, were conducted. For the Ucn 1 priming data, two-way repeated-measure ANOVAs were used to analyze the difference between the treatment conditions with the multiple test sessions used as repeated measures.

The HR and MAP data were expressed as minute-byminute changes from the baseline (an average value of $\mathrm{HR}$ and MAP for $5 \mathrm{~min}$ prior to the experimental procedure) for each rat. Each cardiovascular-dependent variable (ie HR, MAP) was analyzed using a two-way ANOVA with Ucn1 priming as a main factor and time as repeated measures. Analyses were performed on within-subjects for time effects, which were the difference in the change in HR or MAP from the mean of the $5 \mathrm{~min}$ baseline, and betweensubjects for the effects at each individual time point. In all cases, Bonferroni multiple comparison post hoc tests were used for comparing individual means.

\section{Histology}

Following experiments, all rats were anesthetized and decapitated; their brains were removed and frozen; were 
sectioned $(40 \mu \mathrm{m})$; and stained with neutral red for determination of injection cannulae placements.

\section{RESULTS}

\section{Experiment 1: Acute Effects of Ucn1}

BNST. Intra-BNST injection of Ucn1 (see Figure 1a for cannula placements) elicited anxiety-like behavior in rats as measured by reduced SI time in a dose-dependent manner $(n=6)$. A one-way ANOVA showed a significant overall treatment effect $\left(\mathrm{F}_{(3,23)}=20.47, p<0.0001\right)$, and a post hoc test revealed that the animals injected with $20 \mathrm{fmol} \mathrm{Ucn} 1$ showed a significant reduction in SI time compared with vehicle injection $(p<0.01)$, and to their own preinjection baseline interaction time periods $(p<0.01)$. Furthermore, the animals showed a significantly greater reduction in SI time following injection of the $100 \mathrm{fmol}$ compared with $20 \mathrm{fmol}$ dose of Ucn1 $(p<0.05)$, suggesting a dosedependent reduction of SI following CRF receptor activation in the BNST (Figure 2a).

Nucleus accumbens. Injecting the above highest effective dose of Ucn1 (100 fmol) into the nucleus accumbens (see Figure $1 \mathrm{~b}$ for cannula placements) did not have an anxiogenic effect in the SI test compared with preinjection baseline $(n=4 ; p=0.7288)$, suggesting that the anxiogenic effects elicited by Ucn 1 are confined to the region of the BNST, and is not due to diffusion to another adjacent functionally critical region. These data are illustrated in Figure 2b.

\section{Experiment 2: Ucn1 Priming of The BNST}

Unlike the $20 \mathrm{fmol}$ dose of Ucn1, when a $6 \mathrm{fmol}$ dose of Ucn1 was injected into the BNST, it did not alter anxietylike behavior in rats $30 \mathrm{~min}$ following the first injection. Thus, the $6 \mathrm{fmol}$ dose of Ucn 1 was chosen as a subthreshold dose. However, when this initially subthreshold dose was injected once a day, on the fifth injection day, the animals receiving the same 6 -fmol Ucn 1 showed a significant reduction in SI time. Supporting this notion, there was a significant overall time effect $\left(\mathrm{F}_{(2,20)}=4.826\right.$, $p=0.019$ ), and subsequent post hoc testing showed that unilateral injections of Ucn 1 decreased SI time after the fifth injection compared with their preinjection baseline (Figure 3a; $t=3.397, p<0.01$ ).

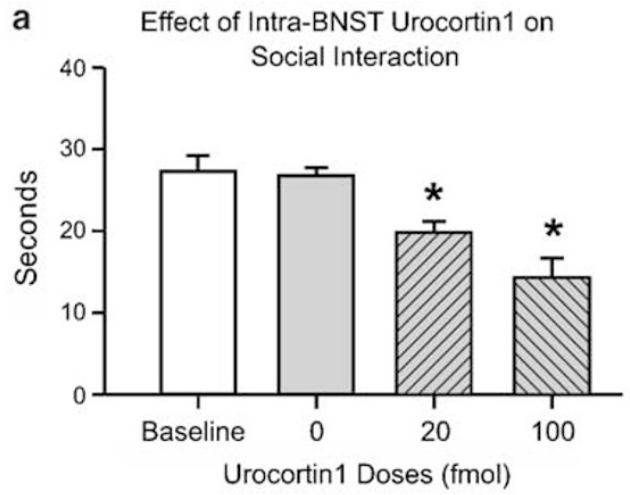

b Intra-Nucleus Accumbens Urocortin1 (100 fmol)

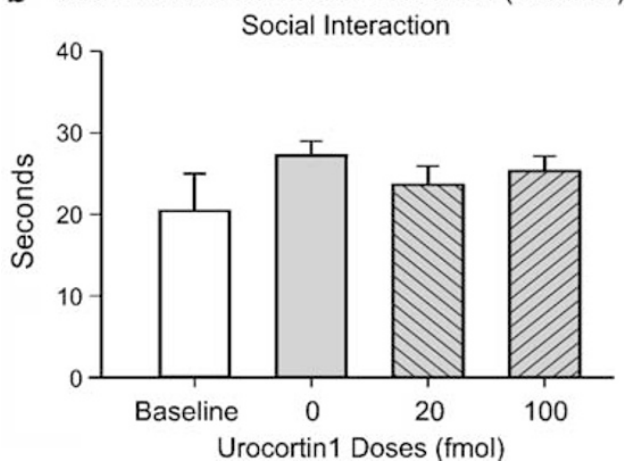

Figure 2 Acute effects of intra-BNST Ucn I injection and anatomical control. Unilateral injection of Ucn I into the BNST reduced SI in a dosedependent manner $(a ; n=6)$. The same range of doses of $U c n \mid$ injected into the nucleus accumbens, the area rostral to the BNST (see Figure la and $b)$, failed to change SI (b; $n=6)$. The asterisk $(*)$ shows statistically significant difference from baseline $(p<0.05)$.
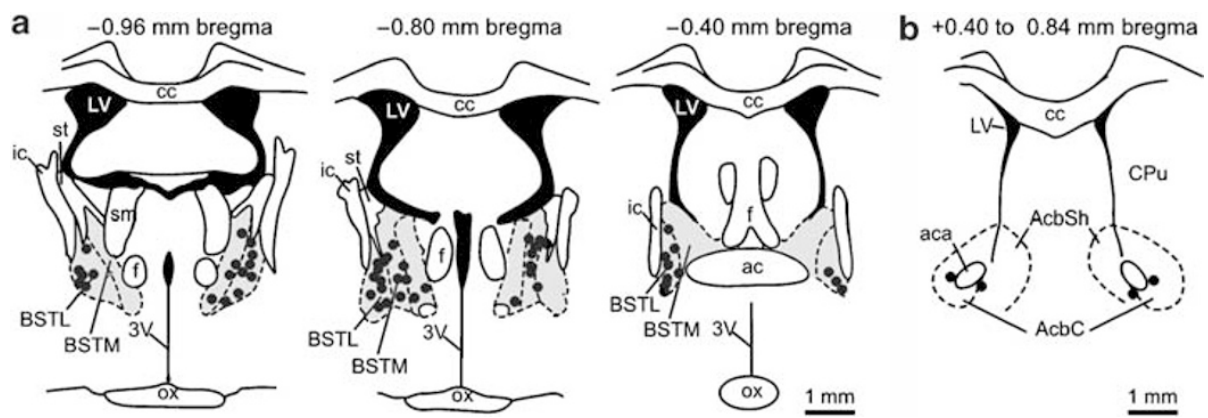

Figure I Histological verification of cannulae placement represented on coronal brain-section illustrations. Representative cannulae placements throughout the rostra-caudal extent of the BNST (a) and nucleus accumbens control injections (b). The gray areas in panel a represent the BNST area. Each black dot represents an injection site from each experiment, which resides within the BNST area. Black dots in (b) represent control injection sites in the nucleus accumbens. The distance from Bregma is indicated above each coronal brain section illustration. A I mm scalebar is located at the bottom right of panel $\mathrm{a}$ and $\mathrm{b}$. The coronal demarcations are adapted from a standard rat brain stereotaxic atlas (Paxinos and Watson, 1986). Abbreviations: 3V, 3rd ventricle; ac, anterior commissure; aca, anterior part of anterior commissure; AcbC, nucleus accumbens core; AcbSh, nucleus accumbens shell; BSTL, bed nucleus of the stria terminalis, lateral division; BSTM, BNST, medial division; cc, corpus collosum; CPu, caudate putamen; f, fornix; ic, internal capsule; LV, lateral ventricle; ox, optic chiasm; sm, stria medullaris of the thalamus; st, stria terminalis. 


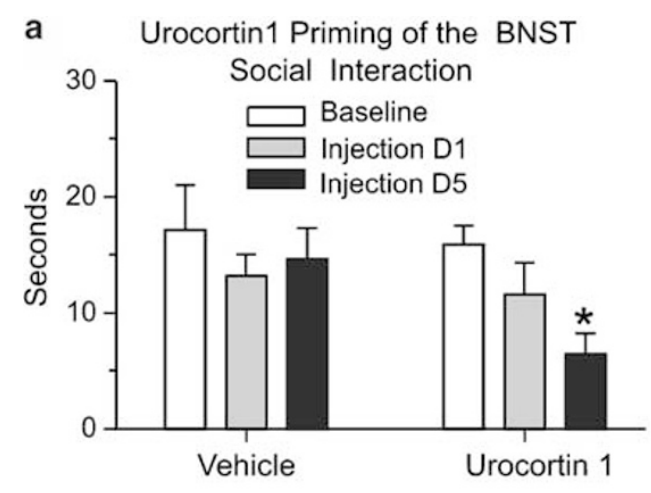

b Urocortin1 Priming of the BNST

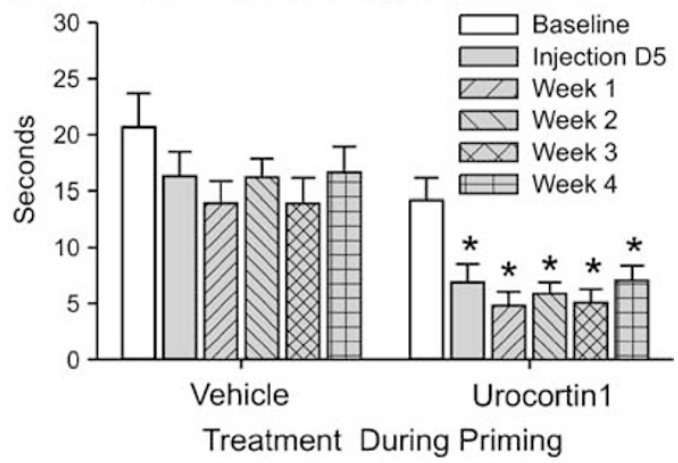

C
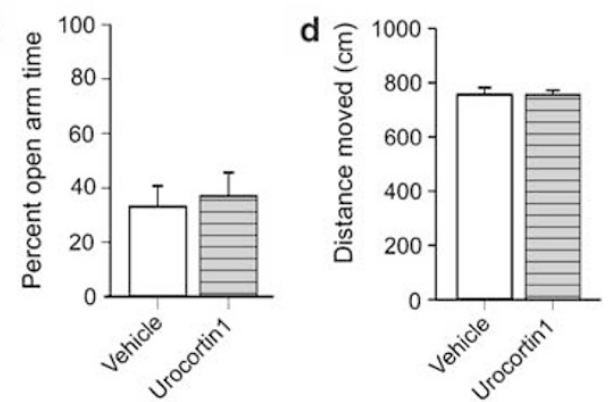

Figure $3 U \mathrm{cn}$ I priming of the BNST. Multiple unilateral $(n=6)$ injections of a subthreshold dose of $\mathrm{Ucn} I$ ( $6 \mathrm{fmol} / \mathrm{I} 00 \mathrm{nl} /$ day/5 days) suppressed $\mathrm{SI}$ time significantly for 4 consecutive weeks ( $a$ and b) without affecting performance in EPM (c). Lack of changes in plus maze does not appear to be resulting from a nonspecific motor deficit as the overall distance traveled by each group was comparable (d). The $(*)$ indicates a significant difference from baseline $(p<0.05)$.

More interestingly, this enhanced anxiety following Ucn1 priming was long lasting; the reduction in SI time in Ucn1 priming group was sustained throughout 4 weeks postpriming test period without any further Ucn1 injection. An overall ANOVA showed a significant main time effect $\left(\mathrm{F}_{(5,45)}=6.807, p<0.0001\right)$ and post hoc tests using Bonferroni's test showed a significant reduction in SI time on day 5 as well as each weekly test $(p<0.001)$ compared with preinjection baseline (Figure $3 \mathrm{~b}$ ).

The anxiety-like behavior elicited by repeated intra-BNST injections of Ucn1 appears selective to the SI test, since the same group of Ucn1-primed animals failed to show reduction in open arm exploration time in EPM test $(p=0.3435$; Figure $3 c)$. This result was not due to differences in locomotor activity, since the total distances traveled by both groups were not different from each other's

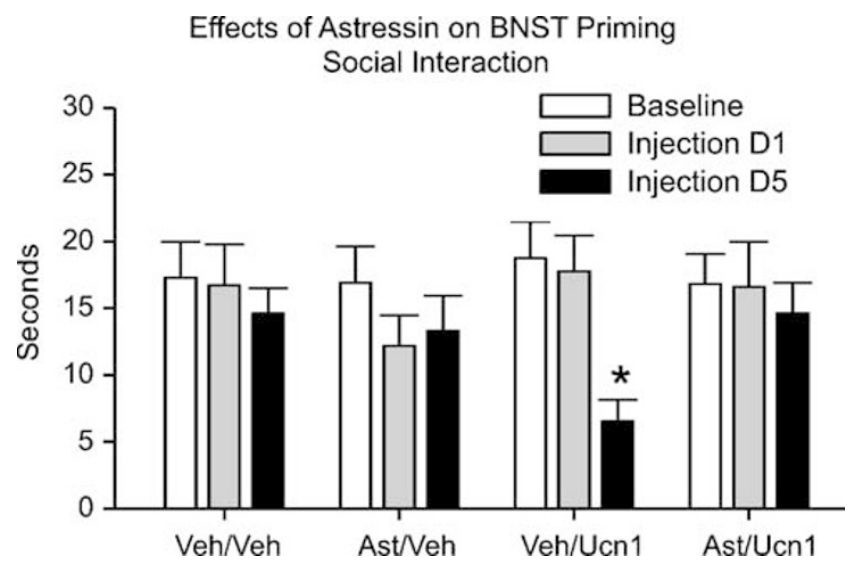

Figure 4 Effects of a CRF antagonist on the BNST priming. Pretreatment with a non-selective CRF receptor antagonist, astressin ( $120 \mathrm{fmol} / \mathrm{l} 00 \mathrm{nl}$ ) 30 min prior to daily $U_{\mathrm{cn}} \mathrm{I}$ injections completely blocked reductions in $\mathrm{SI}$ as a result of $U \mathrm{cnl}$-induced sensitization of the BNST. The $\left(^{*}\right)$ indicates a significant difference from baseline $(p<0.01)$.

distances $(p=0.6124$; Figure $3 \mathrm{~d})$. One of Ucn1-injected group animals was eliminated from data analysis due to the misplacement of cannulae.

\section{Experiment 3: Effects of a CRF Antagonist on Ucn1 Priming of the BNST}

Pretreatment with a nonselective CRF receptor antagonist, astressin, completely blocked development of Ucn1 priming in the BNST (Figure 4). An overall two-way ANOVA with repeated measure showed a significant main time effect $\left(\mathrm{F}_{(2,38)}=4.941, p=0.0124\right)$ among four comparison groups that received astressin or vehicle pretreatment prior to vehicle or Ucn1 priming. The animals that received $120 \mathrm{fmol}$ of astressin prior to Ucn 1 injections did not show reduction in SI on injection day 5 ( $p>0.05$; Bonferroni's post hoc test), whereas animal pretreated with vehicle prior to Ucn1 injections showed a significant reduction in SI time on day 5 compared to preinjection baseline $(t=3.387, p<0.01$; Figure 4). One of the Ucn1 priming groups and vehicle group animals was eliminated from the data analysis due to the misplacement of cannulae.

\section{Experiment 4: Responses to Sodium Lactate Infusions in Rats Following Ucn1 Priming of the BNST}

Consistent with the result from Experiment 2, daily five injections of Ucn1 into the BNST increased anxiety-like behavior in rats (see Figure 5 for timeline of experimental treatments). However, subsequent challenge with sodium lactate did not suppress SI time further, suggesting no change in response sensitivity to sodium lactate infusion in the BNST primed rats. Supporting these notions, an overall two-way ANOVA with repeated measure showed a significant time $\times$ treatment interaction $\quad\left(\mathrm{F}_{(6,33)}=2.607\right.$, $p=0.0352)$ in SI time; Bonferroni post hoc tests showed a significant reduction in SI compared to preinjection saline baseline following 5 day intra-BNST injections of Ucn1 $(t=2.756, p<0.05)$, without significant changes in SI times between last day of priming and post-priming lactate challenge tests (see Figure 6a). Unlike in the BLA, 3-day 


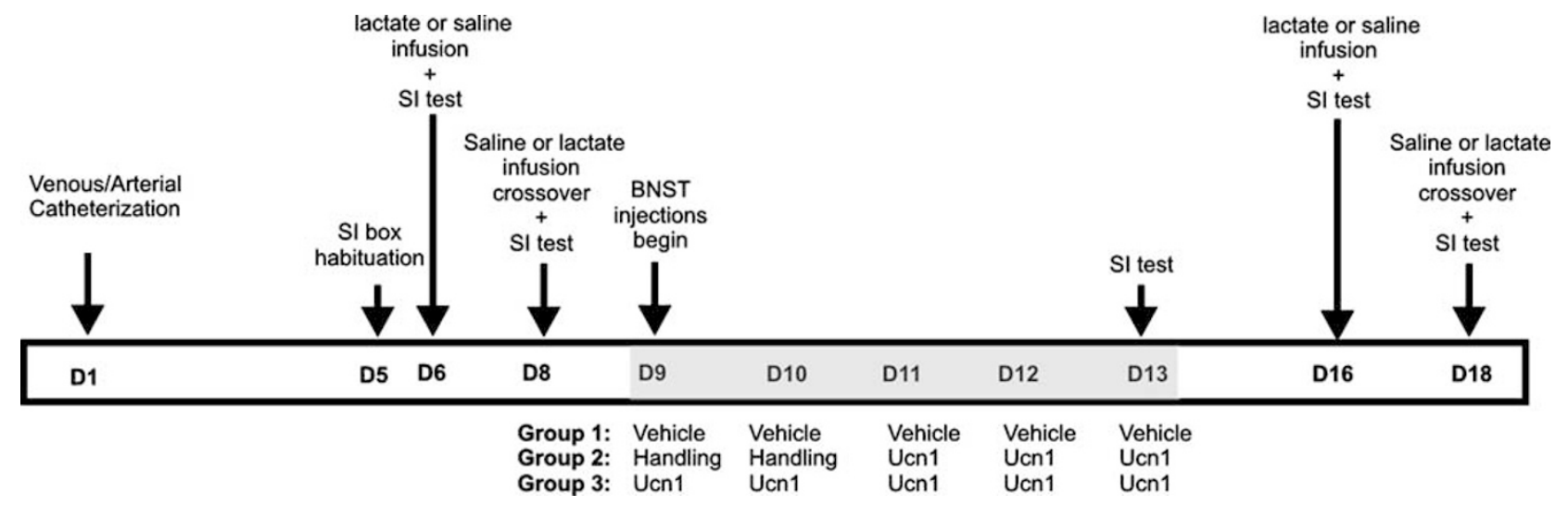

Figure 5 An illustration representing a timeline of experiment 4 and treatment conditions (listed above arrows) from days I (DI) to I8 (DI8) along the horizontal bar. See methods for detailed description. Gray shading of horizontal bar indicates the timeline of BNST injections on D9-DI3 (see details of injections for each group below gray shaded region).

injections of Ucn1 into the BNST did not change the SI time measured 30 min postinjection (data not shown).

The animals treated with daily five injections of Ucn 1 or vehicle also failed to have altered physiological responses to either lactate or saline infusions (BNST treatment effect (HR: $\mathrm{F}_{(1,11)}=0.1, p=0.742$; MAP: $\left.\mathrm{F}_{(1,11)}=0.2, p=0.693\right)$, i.v. infusion effect (HR: $\mathrm{F}_{(1,11)}=0.1, \quad p=0.750$; MAP: $\left.\mathrm{F}_{(1,11)}=0.01, p=0.925\right)$ and BNST treatment $\times$ i.v. Infusion interaction $\left(\mathrm{HR}: \mathrm{F}_{(1,11)}=0.9, p=0.365\right.$; MAP: $\mathrm{F}_{(1,11)}=0.2$, $p=0.687)$ ). These results were not due to the difference in pre-i.v. infusion baselines; all three treatment groups showed comparable baseline HR and MAP levels prior to i.v. infusion $(p<0.05$, please see the insets in Figure $6 \mathrm{~b}$ for actual baselines prior to post-priming i.v. challenges). Again, different from Ucn 1 priming of the BLA, the animals that received daily three injections of Ucn1 into the BNST not only failed to show suppression of SI on the third Ucn1 injection day, but also failed to show physiological responses to lactate infusion (data not shown). Taken together, these data suggest that repeated stimulation of CRF receptors within the BNST changes behavioral anxiety, but the same treatment does not change sensitivity to lactate infusion. Figure $6 \mathrm{~b}$ illustrates these data.

\section{DISCUSSION}

Acute Ucn 1 injections into the BNST dose-dependently increased anxiety-like behavior as measured by reduced SI times, suggesting that local CRF systems in BNST regulates certain types of anxiety-like behaviors. Similar to the effects of Ucnl priming of the BLA, five consecutive injections of a subthreshold dose of Ucn 1 ( $6 \mathrm{fmol} / 100 \mathrm{nl} /$ day) into the BNST induced a persistent anxiety measured by long-lasting suppression in SI times. However, there are interesting differences between the priming of the BNST compared to the priming of the BLA. For instance, priming of the BNSTinduced anxiety-like behavior in SI test without affecting performance in EPM. Considering that the intra-BNST CRF system has been implicated in anxiety responses measured in EPM (Sahuque et al, 2006), the lack of changes in EPM measure in the current study is intriguing. One possible explanation is that CRF injections into the BNST were given bilaterally in the study by Sahuque et al, where as in the present study, priming was done with unilateral injections. Also, the doses of the CRF receptor agonist utilized in those studies were much higher than those employed here. Thus, modulation of SI may occur at a lower threshold compared to modulation of EPM by CRF receptors.

Also, unlike priming in the BLA, which resulted in anxiogenic effects in both SI and EPM, the anxiogenic effects of BNST priming was selective to the SI test. Once again, since BNST priming occurred following unilateral injection whereas bilateral injections were used for priming of the BLA, it is possible that changes elicited following unilateral Ucn1 priming of BNST is not strong enough to drive anxiety responses in EPM. Inputs from the BLA reach the BNST directly or indirectly through the central nucleus of amygdala (CeA) (For review see (Cassell et al, 1999; Dong et al, 2001)). Therefore, it is conceivable that bilateral priming of the BLA, which in turn stimulates bilateral BNST via direct (BLA-BNST) and/or indirect (BLA-CeA-BNST) projections altering responses in EPM. In contrast, unilateral priming of the BNST may change the anxiety threshold only to the level necessary for eliciting behavioral changes in SI measure.

Another intriguing difference between Ucn 1 priming of the BNST and Ucnl priming of the BLA is the response of the rats to post-priming lactate challenge. Unlike the BLAprimed rats, the BNST-primed rats that received daily five injections of Ucn1 did not display panic-like cardiovascular responses following lactate challenges. The lack of sensitivity to lactate challenge is of considerable heuristic importance in classifying anxiety disorders. Intravenous infusion of sodium lactate elicits panic attacks in the majority of panic disorder patients (Reiman et al, 1984; Liebowitz et al, 1985; Gaffney et al, 1988; Strohle et al, 2003) and some PTSD subjects (Rainey et al, 1987; Jensen et al, 1998), but not other anxiety disorders such as obsessive compulsive disorder (Gorman et al, 1985), social anxiety disorder (Liebowitz et al, 1985) or pure depressive disorders (McGrath et al, 1988; Cowley and Arana, 1990). The present study demonstrates that the Ucn1 priming of the BNST induces a persistent increase in anxiety selectively in the SI test without panic-like cardiovascular responses to lactate infusion. In contrast, the rats with Uncl priming in the BLA 
a
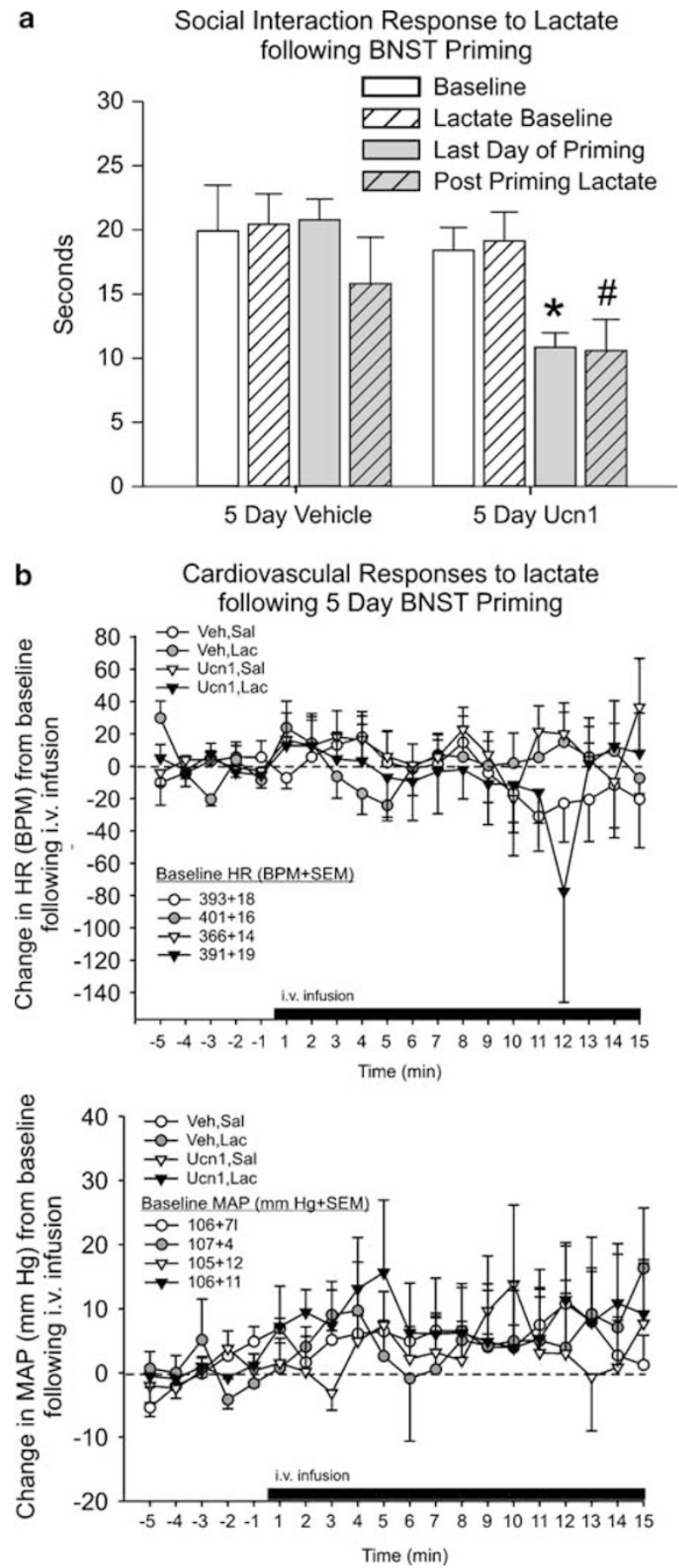

Figure 6 Cardiovascular and behavioral responses to lactate following the BNST priming. Daily five injections of $U \mathrm{cnl}$ into the BNST induced a significant reduction in social interaction (SI: see a), whereas three daily injections did not (data not shown, see results section). Infusion of sodium lactate $(0.5 \mathrm{M}, 10 \mathrm{ml} / \mathrm{kg})$ did not further suppress $\mathrm{SI}$ in 5 days (a) or 3 days (data not shown, see results section) Ucn I primed rats. The $\left(^{*}\right)$ indicates a significant difference in SI from the baseline $(p<0.05)$, and the $(\#)$ represents a significant difference from lactate baseline $(p<0.05)$. Neither sodium lactate nor saline infusion (i.v.) altered $\mathrm{HR}$ or mean arterial pressure responses in 5 days (b) or 3 days (data not shown, see results section) Ucnl-treated rats. Analyses were done on within-subjects time effects (which were the difference in the change in HR or MAP from the mean of the $5 \mathrm{~min}$ baseline) and between-subjects effects at each individual time point. showed cardiovascular sensitivity to peripheral lactate (Sajdyk et al, 1999; Rainnie et al, 2004). Taken together, these data suggest that the BNST may be critical for acquisition and expression of the persistent social anxiety state without the physiological sensitivity to lactate challenge, providing a putative model for social anxiety disorder.

A technical consideration to be noted while utilizing SI test to measure 'social' anxiety is the significant differences noted in this response within different strains of rats. In our previous studies utilizing Wistar rats, baseline SI duration ranged from 15 to $35 \mathrm{~s}$, with a median duration of about $25 \mathrm{~s}$ (Sanders and Shekhar, 1995a; Sajdyk et al, 1999; Rainnie et al, 2004). In contrast, when we have utilized SpragueDawley rats, the baseline SI durations range from 40 to $70 \mathrm{~s}$, with a median duration of about $50 \mathrm{~s}$ (Shekhar and Katner, 1995; Shekhar et al, 1996). Thus, the low level of baseline SI displayed by Wistar rats in the current studies are comparable to previous studies, but are substantially lower than baseline SI duration displayed by Sprague-Dawley strains of rats. Also, all of our present and previous behavior tests were conducted during light phase (between $9 \mathrm{am}$ and $1 \mathrm{pm}$ ) of the day, when rats are generally less active. We might also see increased baseline SI durations if the behavioral tests were conducted during the dark phase of the light/dark cycle when the rats are naturally more active.

The CRF system in the BNST is also an integral part of the circuitry responsible for stress modulation of drug-seeking behavior. It is well established that the activation of central CRF system is essential for stress-induced reinstatement of drug-seeking behavior (Shaham et al, 1997; Le et al, 2000; Shalev et al, 2006), and CRF receptor antagonism blocks this stress effect (Shaham et al, 1998). Identifying the BNST as a key structure for mediating this phenomenon, Erb and Stewart reported that stress-induced reinstatement of drugseeking behavior is mimicked by an intra-BNST injection of CRF and blocked by an intra-BNST injection of a CRF antagonist, D-Phe $\mathrm{CRF}_{12-41}$ (Erb and Stewart, 1999). Addiction vulnerability is commonly correlated with pathophysiology of many mental disorders (Kushner et al, 2000; Chambers et al, 2001; Zvolensky and Schmidt, 2004; Brady and Verduin, 2005), and substantial data demonstrates high comorbidity between social anxiety disorder and alcohol dependence. If CRF modulation of the BNST is a key biological mechanism for development of a persistent state of elevated social anxiety, and if stimulation of CRF neurotransmission within the BNST modulates drug-seeking behavior, then Ucn1 priming of the BNST could prove to be a useful tool to investigate a common mechanism for increased vulnerability for substance abuse and psychiatric disorders.

BNST is known to contain both CRF1 and CRF2 types of receptors. Both the CRF receptor agonist (Ucn1) and the antagonist (astressin) utilized in the current studies have high affinities for both types of CRF receptors. Thus, whether these priming effects are the results of activating a specific CRF receptor subtype remains to be clarified. Our preliminary data utilizing selective antagonists demonstrate that the anxiogenic effect elicited by Ucn 1 in the SI test is mediated by the CRF1 and not the CRF2 receptors (Y Lee et al, unpublished results). This is consistent with the 
results of Sahuque et al, 2006, demonstrating that the anxiogenic effects of CRF in the BNST was mediated by CRF1 receptors, where as the stress-induced reinstatement of drug-seeking behavior was mediated by both CRF1 and CRF2 receptors.

The underlying mechanism responsible for the longlasting anxiety elicited by intra-BNST injections of Ucnl is unknown at present. One possibility is that the activitydependent long-term potentiation (LTP)-like phenomenon may occur following the multiple Ucn1 injections. A previous study from our laboratory demonstrated that repeated CRF receptor activation in the BLA results in an NMDA receptor-mediated activation of the calcium-calmodulin-dependent protein kinase II (CaMKII) cascade that is critical for the priming effects in the BLA (Rainnie et al, 2004). Considering the major role played by both the NMDA receptor and the CaMKII signaling pathway in the development of synaptic plasticity ((Clugnet and LeDoux, 1990; Tan and Liang, 1997); and for reviews, see (Collingridge and Bliss, 1995; Nicoll and Malenka, 1999; Lisman et al, 2002)), these data suggest that the behavioral plasticity observed after repeated activation of the BLA may be driven by an LTP-like phenomenon following CRF $_{1}$ activation. Whether Ucn1 priming of the BNST utilizes a similar cellular mechanism remains to be investigated.

In summary, repeated subanxiogenic dose of Ucn1 injections (priming) into the BNST of rats induces selective expression of anxiogenic-like effects in the SI but not the EPM test. Unlike rats subjected to Ucn1 priming in the amygdala, those primed in the BNST also failed to demonstrate increased HR and MAP responses following lactate infusion. Thus, priming with Ucn1 in the BNST may uniquely model the pathophysiology of select anxiety syndromes like social anxiety disorder, one of the anxiety disorders where the subjects experience anxiety only in specific social situations and do not demonstrate sensitivity to intravenous lactate infusions.

\section{ACKNOWLEDGEMENTS}

This research was supported by ADAA Junior Faculty Research Grant (YL) and NIMH R01 s MH065702 and MH52619 (AS). We thank Colleen Merrill and Amy Dietrich for excellent technical help.

\section{DISCLOSURE}

The present work was supported by the National Institute of Mental Health (RO1 MH065702 and RO1 MH052619 to AS) and the Anxiety Disorders Association of America (Junior Faculty Research Award to YL). The authors' have no other disclosures to report.

\section{REFERENCES}

Aston-Jones G, Harris GC (2004). Brain substrates for increased drug seeking during protracted withdrawal. Neuropharmacology 47: 167-179.

Baldwin HA, Rassnick S, Rivier J, Koob GF, Britton KT (1991). CRF antagonist reverses the 'anxiogenic' response to ethanol withdrawal in the rat. Psychopharmacology (Berl) 103: 227-232.
Brady KT, Verduin ML (2005). Pharmacotherapy of comorbid mood, anxiety, and substance use disorders. Subst Use Misuse 40: 2021-2041, 2043-2028.

Britton DR, Koob GF, Rivier J, Vale W (1982). Intraventricular corticotropin-releasing factor enhances behavioral effects of novelty. Life Sci 31: 363-367.

Britton KT, Morgan J, Rivier J, Vale W, Koob GF (1985). Chlordiazepoxide attenuates response suppression induced by corticotropin-releasing factor in the conflict test. Psychopharmacology 86: 170-174.

Cassell MD, Freedman LJ, Shi C (1999). The intrinsic organization of the central extended amygdala. Ann NY Acad Sci 877: 217-241.

Chalmers DT, Lovenberg TW, De Souza EB (1995). Localization of novel corticotropin-releasing factor receptor (CRF2) mRNA expression to specific subcortical nuclei in rat brain: comparison with CRF1 receptor mRNA expression. J Neurosci 15: 6340-6350.

Chambers RA, Krystal JH, Self DW (2001). A neurobiological basis for substance abuse comorbidity in schizophrenia. Biol Psychiatry 50: 71-83.

Clugnet MC, LeDoux JE (1990). Synaptic plasticity in fear conditioning circuits: induction of LTP in the lateral nucleus of the amygdala by stimulation of the medial geniculate body. J Neurosci 10: 2818-2824.

Cole BJ, Koob GF (1988). Propranolol antagonizes the enhanced conditioned fear produced by corticotropin releasing factor. J Pharmacol Exp Ther 247: 902-910.

Collingridge GL, Bliss TV (1995). Memories of NMDA receptors and LTP. Trends Neurosci 18: 54-56.

Cowley DS, Arana GW (1990). The diagnostic utility of lactate sensitivity in panic disorder. Arch Gen Psychiatry 47: 277-284.

Cullinan WE, Herman JP, Watson SJ (1993). Ventral subicular interaction with the hypothalamic paraventricular nucleus: evidence for a relay in the bed nucleus of the stria terminalis. J Comp Neurol 332: 1-20.

Dautzenberg FM, Hauger RL (2002). The CRF peptide family and their receptors: yet more partners discovered. Trends Pharmacol Sci 23: 71-77.

Davis M, Shi C (1999). The extended amygdala: are the central nucleus of the amygdala and the bed nucleus of the stria terminalis differentially involved in fear vs anxiety? Ann NY Acad Sci 877: 281-291.

De Souza EB, Insel TR, Perrin MH, Rivier J, Vale WW, Kuhar MJ (1985). Corticotropin-releasing factor receptors are widely distributed within the rat central nervous system: an autoradiographic study. J Neurosci 5: 3189-3203.

Dong HW, Petrovich GD, Swanson LW (2001). Topography of projections from amygdala to bed nuclei of the stria terminalis. Brain Res Brain Res Rev 38: 192-246.

Dunn AJ, File SE (1987). Corticotropin-releasing factor has an anxiogenic action in the social interaction test. Hormones of Behavior 21: 193-202.

Erb S, Stewart J (1999). A role for the bed nucleus of the stria terminalis, but not the amygdala, in the effects of corticotropinreleasing factor on stress-induced reinstatement of cocaine seeking. J Neurosci 19: RC35.

Fendt M, Endres T, Apfelbach R (2003). Temporary inactivation of the bed nucleus of the stria terminalis but not of the amygdala blocks freezing induced by trimethylthiazoline, a component of fox feces. J Neurosci 23: 23-28.

File SE (1980). The use of social interaction as a method for detecting anxiolytic activity of chlordiazepoxide-like drugs. J Neurosci Methods 2: 219-238.

Forray MI, Gysling K (2004). Role of noradrenergic projections to the bed nucleus of the stria terminalis in the regulation of the hypothalamic-pituitary-adrenal axis. Brain Res Brain Res Rev 47: 145-160. 
Gaffney FA, Fenton BJ, Lane LD, Lake CR (1988). Hemodynamic, ventilatory, and biochemical responses of panic patients and normal controls with sodium lactate infusion and spontaneous panic attacks. Arch Gen Psychiatry 45: 53-60.

Gorman JM, Liebowitz MR, Fyer AJ, Dillon D, Davies SO, Stein J et al (1985). Lactate infusions in obsessive compulsive disorder. Am J Psychiatry 142: 864-866.

Herman JP, Mueller NK, Figueiredo H (2004). Role of GABA and glutamate circuitry in hypothalamo-pituitary-adrenocortical stress integration. Ann NY Acad Sci 1018: 35-45.

Jensen CF, Keller TW, Peskind ER, McFall ME, Veith RC, Martin D et al (1997). Behavioral and neuroendocrine responses to sodium lactate infusion in subjects with posttraumatic stress disorder. Am J Psychiatry 154: 266-268.

Jensen CF, Peskind ER, Keller TW, McFall ME, Raskind MA (1998). Comparison of sodium lactate-induced panic symptoms between panic disorder and posttraumatic stress disorder. Depress Anxiety 7: 122-125.

Kushner MG, Abrams K, Borchardt C (2000). The relationship between anxiety disorders and alcohol use disorders: a review of major perspectives and findings. Clin Psychol Rev 20: 149-171.

Le AD, Harding S, Juzytsch W, Watchus J, Shalev U, Shaham Y (2000). The role of corticotrophin-releasing factor in stressinduced relapse to alcohol-seeking behavior in rats. Psychopharmacology (Berl) 150: 317-324.

Lee Y, Davis M (1997). Role of the hippocampus, the bed nucleus of the stria terminalis, and the amygdala in the excitatory effect of corticotropin-releasing hormone on the acoustic startle reflex. J Neurosci 17: 6434-6446.

Leri F, Flores J, Rodaros D, Stewart J (2002). Blockade of stressinduced but not cocaine-induced reinstatement by infusion of noradrenergic antagonists into the bed nucleus of the stria terminalis or the central nucleus of the amygdala. J Neurosci 22: 5713-5718.

Liang KC, Lee EH (1988). Intra-amygdala injections of corticotropin releasing factor facilitate inhibitory avoidance learning and reduce exploratory behavior in rats. Psychopharmacology (Berl) 96: 232-236.

Liang KC, Melia KR, Miserendino MJ, Falls WA, Campeau S, Davis M (1992). Corticotropin-releasing factor: long-lasting facilitation of the acoustic startle reflex. J Neurosci 12: 2303-2312.

Liebowitz MR, Fyer AJ, Gorman JM, Dillon D, Davies S, Stein JM et al (1985). Specificity of lactate infusions in social phobia $v s$ panic disorders. Am J Psychiatry 142: 947-950.

Lisman J, Schulman H, Cline H (2002). The molecular basis of CaMKII function in synaptic and behavioural memory. Nat Rev Neurosci 3: 175-190.

McGrath PJ, Stewart JW, Liebowitz MR, Markowitz JM, Quitkin FM, Klein DF et al (1988). Lactate provocation of panic attacks in depressed outpatients. Psychiatry Res 25: 41-47.

Nicoll RA, Malenka RC (1999). Expression mechanisms underlying NMDA receptor-dependent long-term potentiation. Ann NY Acad Sci 868: 515-525.

Paxinos G, Watson C (1986). The Rat Brain Stereotaxic Coordinates. Academic Press: New York.

Perrin MH, Vale WW (1999). Corticotropin releasing factor receptors and their ligand family. Ann NY Acad Sci 885: 312-328.

Rainey Jr JM, Aleem A, Ortiz A, Yeragani V, Pohl R, Berchou R (1987). A laboratory procedure for the induction of flashbacks. Am J Psychiatry 144: 1317-1319.

Rainnie DG, Bergeron R, Sajdyk TJ, Patil M, Gehlert DR, Shekhar A (2004). Corticotrophin releasing factor-induced synaptic plasticity in the amygdala translates stress into emotional disorders. J Neurosci 24: 3471-3479.

Reiman EM, Raichle ME, Butler FK, Herscovitch P, Robins E (1984). A focal brain abnormality in panic disorder, a severe form of anxiety. Nature 310: 683-685.
Sahuque LL, Kullberg EF, McGeehan AJ, Kinder JR, Hicks MP, Blanton MG et al (2006). Anxiogenic and aversive effects of corticotropin-releasing factor (CRF) in the bed nucleus of the stria terminalis in the rat: role of CRF receptor subtypes. Psychopharmacology (Berl) 186: 122-132.

Sajdyk TJ, Schober DA, Gehlert DR, Shekhar A (1999). Role of corticotropin-releasing factor and urocortin within the basolateral amygdala of rats in anxiety and panic responses. Behav Brain Res 100: 207-215.

Sajdyk TJ, Shekhar A (1997). Excitatory amino acid receptor antagonists block the cardiovascular and anxiety responses elicited by gamma-aminobutyric acid A receptor blockade in the basolateral amygdala of rats. J Pharmacol Exp Ther 283: 969-977.

Sanders SK, Shekhar A (1995a). Regulation of anxiety by GABAA receptors in the rat amygdala. Pharmacol Biochem Behav 52: 701-706.

Sanders SK, Shekhar A (1995b). Anxiolytic effects of chlordiazepoxide blocked by injection of GABAA and benzodiazepine receptor antagonists in the region of the anterior basolateral amygdala of rats. Biol Psychiatry 37: 473-476.

Shaham Y, Erb S, Leung S, Buczek Y, Stewart J (1998). CP-154,526, a selective, non-peptide antagonist of the corticotropin-releasing factor1 receptor attenuates stress-induced relapse to drug seeking in cocaine- and heroin-trained rats. Psychopharmacology (Berl) 137: 184-190.

Shaham Y, Funk D, Erb S, Brown TJ, Walker CD, Stewart J (1997). Corticotropin-releasing factor, but not corticosterone, is involved in stress-induced relapse to heroin-seeking in rats. J Neurosci 17: 2605-2614.

Shalev U, Finnie PS, Quinn T, Tobin S, Wahi P (2006). A role for corticotropin-releasing factor, but not corticosterone, in acute food-deprivation-induced reinstatement of heroin seeking in rats. Psychopharmacology (Berl) 187: 376-384.

Shekhar A, Katner JS (1995). Dorsomedial hypothalamic GABA regulates anxiety in the social interaction test. Pharmacol Biochem Behav 50: 253-258.

Shekhar A, Keim SR, Simon JR, McBride WJ (1996). Dorsomedial hypothalamic GABA dysfunction produces physiological arousal following sodium lactate infusions. Pharmacol Biochem Behav 55: 249-256.

Strohle A, Romeo E, di Michele F, Pasini A, Hermann B, Gajewsky G et al (2003). Induced panic attacks shift gamma-aminobutyric acid type A receptor modulatory neuroactive steroid composition in patients with panic disorder: preliminary results. Arch Gen Psychiatry 60: 161-168.

Swerdlow NR, Geyer MA, Vale WW, Koob GF (1986). Corticotropin-releasing factor potentiates acoustic startle in rats: blockade by chlordiazepoxide. Psychopharmacology 88: 147-152.

Takahashi LK, Kalin NH, Vanden Burgt JA, Sherman JE (1989). Corticotropin-releasing factor modulates defensive-withdrawal and exploratory behavior in rats. Behav Neurosci 103: 648-654.

Tan SE, Liang KC (1997). Inhibitory avoidance learning alters the amygdala calcium/calmodulin-dependent protein kinase II activity in rats. Brain Res 748: 227-233.

Van Pett K, Viau V, Bittencourt JC, Chan RK, Li HY, Arias C et al (2000). Distribution of mRNAs encoding CRF receptors in brain and pituitary of rat and mouse. J Comp Neurol 428: 191-212.

Walker DL, Davis M (1997). Double dissociation between the involvement of the bed nucleus of the stria terminalis and the central nucleus of the amygdala in startle increases produced by conditioned $v s$ unconditioned fear. J Neurosci 17: 9375-9383.

Zvolensky MJ, Schmidt NB (2004). Anxiety and substance use disorders: introduction to the special series. J Anxiety Disord 18: 1-6. 